\author{
Espacio y Desarrollo N ${ }^{\circ} 27,2015$, pp. 7-31 (ISSN 1016-9148) \\ http://dx.doi.org/10.18800/espacioydesarrollo.201501.001
}

\title{
ESTUDIO DE LA PERCEPCIÓN SOCIAL DEL TERRITORIO Y DE LOS SERVicios eCOSISTÉmicos en el Alto MaYo, Región San Martín, Perú
}

\author{
Daniele Codato* \\ Universidad de los Estudios de Padova (Italia) \\ danielcod@hotmail.it, danielecod@gmail.com
}

\section{Resumen}

Los servicios ecosistémicos (SE) son definidos como los servicios que el capital natural provee a los seres humanos. Los valores sociales de los SE se pueden definir como la percepción sociocultural del bienestar humano brindado por los ecosistemas. Se está reconociendo cada vez más la importancia de la inclusión de los SE, del conocimiento de los actores locales y de brindar a los tomadores de decisiones una estimación de los valores sociales percibidos, además de los económicos o biofísicos, para evaluar el rango completo de valores ecosistémicos.

El Alto Mayo, en la región de San Martín, es parte de una cuenca andino-amazónica con características peculiares y gran proveedora de diferentes $\mathrm{SE}$, pero también es un territorio bajo grandes transformaciones con diferentes impactos negativos sobre su capital natural y humano que podrían llevar a una disminución de la calidad de vida de su población. En los últimos diez años, el Gobierno Regional de San Martín, con la colaboración de diferentes ONG, ha empezado diferentes iniciativas para revertir los procesos de degradación ambiental en el área.

Este artículo presenta parte de una investigación orientada a estudiar el conocimiento y la percepción de los actores locales sobre el territorio del Alto Mayo y sus SE que pueda contribuir a la conservación de los ecosistemas del área. Se da amplio espacio a la metodología de trabajo utilizada, es decir, el estudio a través de cuestionarios, entrevistas y mapeo participativo a diferentes actores del área y el uso de la herramienta SIG «the Social Values for Ecosystem Services - SolVES».

Palabras clave: valor social de los servicios ecosistémicos, Alto Mayo, mapeo participativo, SolVES.

Doctor en Geografía por la Escuela de doctorado en «Scienze Storiche, Geografiche e Antropologiche» dirección «Geografia Umana e Fisica», Universidad de los Estudios de Padova (Italia). 
Study of social perception of the territory and Ecosystem Services in Alto Mayo, San Martín Region, Peru

\section{Abstract}

Ecosystem services (ES) are defined as the benefits people obtain from ecosystems. Social values of ES may be described as the socio-cultural perception of human well-being provided by ecosystems. The inclusion of the ES is being acknowledged as very important, as well as the local actors knowledge and getting an estimation of the perceived social, economic or biophysics values in order to evaluate the complete range of ecosystem values.

Alto Mayo, in San Martín Region, is part of an Andean-Amazon watershed which offers a great variety of ES and unusual characteristics; it is also a territory that is under major transformations with different negative impacts both on human and natural capital, which could lead to a decline in the quality of life of its population. In the last ten years the Regional Government of San Martín, along with the collaboration of various NGO, has carried out several initiatives to revert environmental degradation of the area.

This paper presents part of a research project which aims to study the knowledge and perception of local actors within the Alto Mayo territory and the ES. The project's purpose is to contribute to the conservation of ecosystems in the area. We focus on the work methodology used, that is, the study conducted through questionnaires, interviews and participatory mapping with various actors in the area and the use of the GIS tool «the Social Values for Ecosystem Services - SolVES».

Key words: social value of ecosystem services, Alto Mayo, participatory mapping, SolVES.

\section{INTRODUCCIón}

El concepto de bienes y servicios ecosistémicos — de aquí en adelante servicios ecosistémicos (SE)_, es decir, los servicios que el capital natural provee a los seres humanos (e.g. secuestro de carbono, agua en cantidad y calidad, comida y combustibles, servicios culturales, etc.), se ha desarrollado desde finales de los años setenta, inicialmente con el propósito de aumentar el interés del público hacia la conservación y hacia la importancia de los ecosistemas para el bienestar humano. Durante los años noventa se incrementó el interés en los SE, sobre todo respecto a su declinación económica y al avance de metodologías de valoración monetaria. Sin embargo, es principalmente después de la segunda mitad de los años 2000 que el concepto alcanza una notoriedad internacional, también en la agenda política, sobre todo gracias a la publicación del Millenium Ecosystem Assessment en 2005, que consiste en un trabajo integral sobre la evaluación de los ecosistemas que involucra diferentes actores públicos, privados y académicos, y que intenta sistematizar y aclarar el concepto de SE, las diferentes metodologías de evaluación y la relación entre ecosistemas y bienestar humano (Millenium Ecosystem Assesment - MA, 2005; Gómez-Baggethun et al., 2010). Junto a la evolución de la valoración económica (utilitarista) de los SE (Costanza et al., 1997) 
y a la creación de mercados y esquemas de pago o compensación por SE sometidos a diferentes avances y críticas, se ha desarrollado todo un área de medición, evaluación y valoración no económica, que tiene en cuenta otros factores, como los biofísicos y ecológicos y, sobre todo en estos últimos años, los socioculturales (Bagstad et al., 2013). Una contribución importante en la construcción de este proceso se da por el uso de herramientas de Sistemas de Información Geográfica (SIG) (Burkhard et al., 2012; Busch et al., 2012) y de SIG participativo (SIGP) (Brown, 2005; Dunn, 2007; Brown et al., 2012), que, entre otros, permiten el levantamiento de información geográfica, el desarrollo de análisis espaciales de los datos y la producción de mapas que apoyan en la visualización y difusión de los resultados.

En los actuales procesos de evaluación de ecosistemas, gestión ambiental y ordenamiento territorial, se está reconociendo cada vez más la importancia de la inclusión de los SE, del conocimiento de los actores locales y de brindar a los tomadores de decisiones una estimación de los valores sociales percibidos, además de los económicos o biofísicos para evaluar el rango completo de valores ecosistémicos (Sherrouse et al., 2011; Van Riper et al., 2012). Los valores sociales se pueden definir como la percepción sociocultural del bienestar humano brindado por los ecosistemas (MA, 2005).

Asimismo, estos conceptos se han incluido progresivamente en la evolución de las políticas y metodologías de ordenamiento territorial y gestión ambiental en el Perú. Un reciente ejemplo del interés político hacia los SE llega desde el Ministerio del Ambiente del Perú, que ha aprobado a través de una resolución ministerial la «Guía Metodológica para la Elaboración de los Instrumentos Técnicos Sustentatorios para el Ordenamiento Territorial (OT)», donde entre los Estudios Especializados se encuentra el «Estudio de Servicios Ecosistémicos» (Minam, 2013).

El Alto Mayo, que comprende las provincias de Rioja y Moyobamba en la Región San Martín, es parte de una cuenca andino-amazónica con características peculiares y gran proveedora de diferentes $\mathrm{SE}$, pero también es un territorio bajo grandes trasformaciones con diferentes impactos negativos sobre su capital natural y humano. Todo esto podría llevar a una disminución de la calidad de vida de la población del Alto Mayo que podría encontrarse privada de estos importantes SE. En los últimos diez años el Gobierno Regional de San Martín, con la colaboración de diferentes ONG y agencias de cooperación, ha empezado diferentes iniciativas para revertir los procesos de degradación ambiental hacia «San Martín Región Verde al 2021».

Este artículo es producto de una ponencia presentada durante el " $\mathrm{X}^{\circ}$ Congreso Nacional y V Congreso de Geografía de las Américas Dr. Efraín Orbegoso Rodríguez», desarrollado desde el 3 hasta el 5 de octubre de 2013 en la ciudad de Trujillo. En esta ponencia se presentó un proyecto de investigación, en ese momento aun inconcluso, que trataba de evaluar el conocimiento y la percepción de ciertos actores locales sobre el territorio del Alto Mayo y sus SE, con el objetivo de contribuir a la conservación de los 
ecosistemas de este área. Por ello se presentará a continuación la metodología de trabajo y algunos resultados obtenidos en esta investigación hasta julio de 2013. En particular se quiere focalizar la atención en la parte de la investigación que concierne al estudio de los valores sociales de los $\mathrm{SE}$ así como los percibidos por ciertos actores locales a través de la utilización del mapeo participativo y la elaboración de mapas con el soporte de la herramienta SIG de modelación «the Social Values for Ecosystem Services - SolVES».

\section{Materiales y métodos}

\section{Área de estudio}

La Región de San Martín, con una superficie de 51465 kilómetros cuadrados y una población estimada en 2013 de cerca de 800000 habitantes, se encuentra en la parte nororiental del Perú, en el lado andino-amazónico de la cordillera de los Andes (Gobierno Regional de San Martín et al., 2009; INEI, 2013) (Figura 1).

El área de estudio corresponde al territorio conocido como Alto Mayo, es decir la parte alta de la cuenca hidrográfica del río Mayo, que se ubica en el noroeste de la Región de San Martín (Figura 1), mientras un 8,8\% del territorio de la cuenca se encuentra en la Región de Amazonas y no se toma en cuenta en esta investigación.

La zona del Alto Mayo comprende la totalidad de las provincias de Rioja y Moyobamba, que se extienden por 7400 kilómetros cuadrados con altitudes entre 190 y 4000 metros sobre el nivel del mar, área que a su vez está dividida políticamente en 15 distritos, como se puede apreciar en la figura 3. El valle creado por el río Mayo es muy extenso, rodeado por montañas de fuerte pendiente y con un fondo de valle amplio y relativamente plano recorrido por una densa red hidrográfica (Proyecto Segunda Comunicación Nacional de Cambio Climático, 2009).

La ubicación geográfica, la orografía y el clima, con una temperatura promedio de $22{ }^{\circ} \mathrm{C}$ y precipitaciones entre 650 y $3500 \mathrm{~mm}$ (la estación más lluviosa se coloca entre diciembre y mayo), han permitido el desarrollo de una gran variedad de ecosistemas con diferentes formaciones vegetales, especialmente de bosque húmedo montano, bosque húmedo pre-montano y bosques inundables (aguajales y renacales) (Proyecto Segunda Comunicación Nacional de Cambio Climático, 2009). Se puede apreciar la presencia de alrededor de doscientos especies vegetales endémicas y numerosos endemismos animales, además de una amplia variedad de peculiaridades como cascadas, cuevas, aguas termales, diferentes especies de orquídeas que confieren a la zona un gran potencial turístico (Gobierno Regional de San Martín et al., 2007).

En el trascurso de los últimos decenios los ecosistemas originarios del Alto Mayo (como de toda la Región San Martín) han sido profundamente alterados por una fuerte presión antrópica que ha otorgado a la región la triste reputación de área más deforestada del Perú (Figura 1). El Alto Mayo es una de las zonas más críticas de la región, 
presentando una pérdida de más del $34 \%$ de su cobertura vegetal, afectando a su alta diversidad biológica, con diferentes especies amenazadas, una fuerte disminución de la cantidad y calidad de agua disponible y una alta erosión de los suelos especialmente en las zonas con fuertes pendientes (Gobierno Regional de San Martín et al., 2007). Estos factores están llevando a una fuerte disminución de la calidad de vida de las poblaciones asentadas que podrían encontrarse privadas de estos importantes SE. Las causas principales de estos procesos negativos se pueden atribuir a la gran migración de colonos provenientes de la costa y sierra, sobre todo desde los años setenta con la construcción de la carretera Marginal de la Selva que conecta costa y Andes a este territorio. Esta infraestructura, junto con una agresiva política agraria, ha impulsado a la parte más pobre de la población hacia esta área amazónica considerada un espacio verde, libre y rico en agua y recursos que colonizar y aprovechar para la producción de productos de autoconsumo y la exportación de otros como el café, el cacao y el arroz. Al mismo tiempo se ha llevado a cabo la tala de especies forestales de alto valor económico y la proliferación de cultivos ilegales como la coca (Gobierno Regional de San Martín et al., 2007).

Actualmente, el Alto Mayo es un área muy activa social y económicamente donde se localizan alrededor de 263000 personas (sobre la base de la proyección INEI a 2013 hay 140000 habitantes en la provincia de Moyobamba y 123000 en la provincia de Rioja), que se dedican principalmente a la agricultura, ganadería y comercio, de los cuales la mayoría son migrantes llegados en los últimos decenios. La población está distribuida por el 65\% en ámbito urbano, principalmente en la capital regional Moyobamba (la ciudad colonial más antigua de la Amazonía peruana) y en las otras capitales distritales y el resto divido entre más de 400 centros poblados rurales deficitarios de servicios básicos, con un bajo nivel de educación y altos índices de pobreza. También, el comercio ilegal de tierra es muy fuerte, que lleva a los colonos a zonas vírgenes más alejadas y de difícil acceso donde desarrollar sus actividades (Gobierno Regional de San Martín et al., 2007). Otra consecuencia de estas dinámicas se puede encontrar también en el cambio cultural y de estilo de vida de la población indígena instalada en la zona, alrededor de 4000 nativos de etnia awajún que viven en 14 comunidades indígenas. En estos últimos años en los territorios awajún se encuentra la mayor tasa de deforestación del Alto Mayo, debido a la práctica de alquiler de sus tierras a los colonos que las usan para sus cultivos (Pérez Celis, 2011). A todo esto se suman otros proyectos territoriales públicos y privados, sobre todo a partir del Estado central y de instituciones supranacionales, cuales potenciales actividades de explotación de hidrocarburos, minería e infraestructuras de conexión viarias (proyectos IIRSA) entre Perú y Brasil.

En la última década el Gobierno Regional, con la colaboración de varias ONG y agencias de cooperación internacional, ha puesto en marcha varias iniciativas para 
revertir los procesos de degradación ambiental hacia la meta "San Martín Región Verde al 2021» (AMPA, 2012). Algunas de las principales intervenciones conciernen la aprobación y actuación del proceso de Zonificación Ecológico Económica (ZEE) desde 2006 y la promulgación de los lineamientos de Política Territorial de la Región, la creación de la Autoridad Regional Ambiental (ARA) en 2010; la creación de un Sistema Regional de Conservación (SRC) donde se articulan las diferentes modalidades de conservación con las políticas y los actores (Rojas, 2012); la implementación de diferentes proyectos de protección, recuperación y valorización económica de los $\mathrm{SE}$, a través de la creación de esquemas de Compensación por SE hídricos (Quintero, 2010; León et al., 2010), el comienzo de proyectos REDD (Reduction of Emissions from Deforestation and Forest Degradation) tanto a nivel Regional con la conformación de la Mesa REDD, como a nivel de Áreas Naturales Protegidas (Reátegui, 2012).

En particular a través del proceso de ZEE en el Alto Mayo (aprobado en 2008 con ordenanzas municipales de las provincias de Rioja y Moyobamba) se evidencia cómo solo el 19\% de la cuenca tiene características favorables para el desarrollo de actividades agrícolas, ganaderas y de aprovechamiento forestal, mientras el $67 \%$ tendría como vocación la conservación de ecosistemas y la oferta de SE (Gobierno Regional de San Martín et al., 2007). Actualmente, un buen porcentaje del territorio se encuentra bajo alguna forma de tutela, por lo menos en papel, ocupando el Bosque de Protección Alto Mayo (BPAM) instituido en 1987 el 24\%.

\section{Entrevistas y encuestas}

Entre los meses de abril y junio de 2013 se llevaron a cabo una serie de encuestas y entrevistas en el área de estudio, basados sobre una exhaustiva búsqueda bibliográfica de casos similares (Sherrouse et al., 2011; De Marchi y Scolozzi, 2012). Todas las preguntas y la metodología de investigación han sido examinadas, revisadas y adaptadas a la realidad local a través de una serie de reuniones con actores claves que tienen un buen conocimiento del área, además de haber sido previamente ensayadas por medio de una serie de simulaciones de encuestas y entrevistas con personas voluntarias. Para facilitar la comunicación con los actores sociales y optimizar los recursos disponibles, se ha integrado la investigación con una consultoría sobre los SE y la gestión de cuencas que es parte de un proyecto de cinco años denominado «Proyecto Biocuencas» de la ONG Conservación Internacional financiado por el Ministerio de Asuntos Exteriores del Gobierno de Finlandia, que tiene como objetivo alcanzar la gestión sostenible de la cuenca del Alto Mayo. El cuestionario está dirigido a diferentes actores locales de la sociedad civil, mientras la entrevista ha sido elaborada por diferentes actores claves tanto del Gobierno regional y Gobiernos locales como de la sociedad civil para profundizar ciertos aspectos importantes de la gestión del Alto Mayo. 


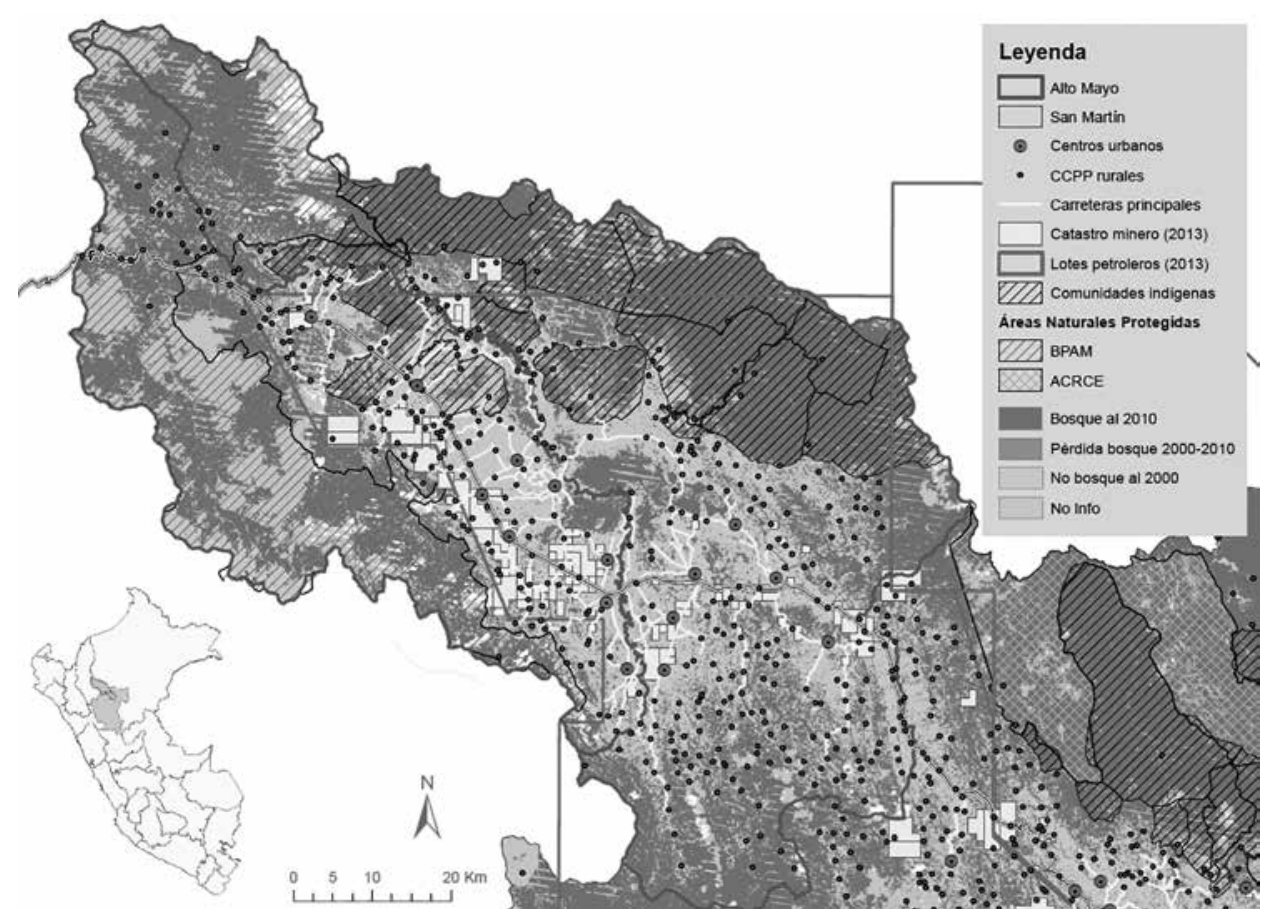

Figura 1. Mapa del Alto Mayo y la región San Martín en el Perú. El mapa evidencia las principales características y presiones antrópicas sobre el área. Fuente: Gobierno Regional de San Martín, Mesa REDD San Martín, Ministerio del Ambiente del Perú. Elaboración: Daniele Codato.

Las preguntas del cuestionario y de la entrevista que directamente interesan los objetivos de esta investigación son:

- Diferentes aspectos concernientes al actor, como su origen y su ubicación actual, si es colono (en este trabajo se entiende por colono a una persona que no ha nacido en el Alto Mayo), mestizo (nacido en el Alto Mayo) o indígena, su profesión, su grado de instrucción, etc.

- La opinión, es decir, si está muy a favor, a favor, neutro, en contra o muy en contra a 14 tipos de actividades o usos posibles que se están desarrollando o podrían desarrollarse en un futuro en el Alto Mayo: explotación minera; explotación petrolera; incremento ganadería; caza, pesca, recolección de productos del bosque bajo manejo-formal; extracción de madera de los bosques protegidos; manejo forestal para la producción de madera; incremento cultivo café/cacao hecho de manera tradicional/monocultivo; incremento cultivo de café/cacao bajo sombra/agroforestal; incremento cultivo de arroz; ecoturismo; creación de áreas de conservación nacionales/regionales; creación de áreas de conservación comunales; colonización e incremento de centros poblados; incremento de carreteras. 
- El ordenamiento de prioridad desde 7 (más importante) hasta 1 (menos importante), de 7 tipos de valores sociales correspondientes a ciertos SE descritos en la tabla 1 .

Tabla 1. Los valores sociales utilizados

\begin{tabular}{|l|}
\hline VALOR SOCIAL \\
\hline $\begin{array}{l}\text { Valor del paisaje: valoro este lugar porque es un sitio bonito, con un paisaje hermoso, buen } \\
\text { olor y sonidos, etc. }\end{array}$ \\
\hline $\begin{array}{l}\text { Valor de diversidad biológica: valoro este lugar porque se encuentran muchas plantas, } \\
\text { animales, peces diferentes. }\end{array}$ \\
\hline $\begin{array}{l}\text { Valor de uso: valoro este lugar porque provee madera, comida, minerales y/o plantas } \\
\text { medicinales }\end{array}$ \\
\hline $\begin{array}{l}\text { Valor de sustento para la vida: valoro este lugar porque permite la producción, preservación } \\
\text { y renovación del agua y del suelo. }\end{array}$ \\
\hline $\begin{array}{l}\text { Valor recreacional: valoro este lugar porque me permite disfrutar de mi tiempo libre haciendo } \\
\text { actividades de diversión con mi familia. }\end{array}$ \\
\hline $\begin{array}{l}\text { Valor espiritual y cultural: valoro este lugar porque es un sitio que me permite continuar y } \\
\text { pasar la sabiduría, conocimientos y tradiciones de mis ancestros y porque es un sitio sagrado, } \\
\text { religioso o espiritualmente importante para mí. }\end{array}$ \\
\hline $\begin{array}{l}\text { Valor histórico: valoro este lugar porque hay sitios y aspectos de la historia natural y humana } \\
\text { del área muy importantes por el pueblo peruano. }\end{array}$ \\
\hline
\end{tabular}

- La identificación en un mapa del Alto Mayo con escala 1:210,000 y formato A2 (Figura 2) de los lugares o áreas donde el actor valoriza más o considera más importantes los valores sociales. Se ha establecido que cada actor pueda identificar un máximo de cuatro lugares o áreas solo para los primeros cinco valores considerados como más importantes. Además, a cada uno de ellos se le pedía el nombre de esta área o lugar o el nombre del lugar conocido más cercano.

- Otros conocimientos sobre aspectos de utilidad, gestión y otros aspectos generales del Alto Mayo, como la presencia de áreas naturales protegidas, de proyectos de conservación, el conocimiento y la participación en el proceso de zonificación ecológico económica y ordenamiento territorial (ZEE-OT), el involucramiento en alguna organización social, la recolección de productos del bosque o el desarrollo de alguna actividad en el campo, la percepción del estado del área como el nivel de deforestación, el estado de los ríos, etc.

En fase de gabinete se ha planeado efectuar 400 encuestas y 106 entrevistas. 


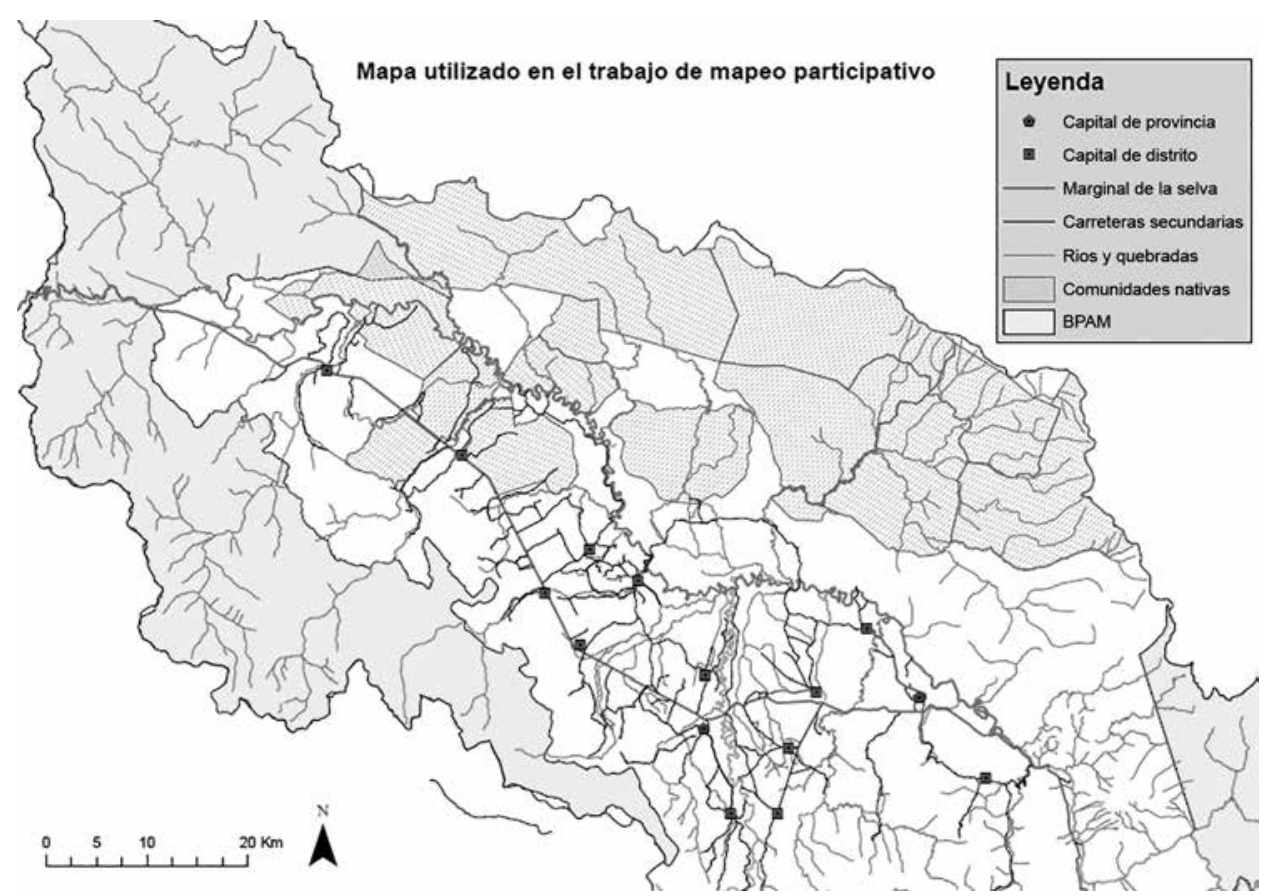

Figura 2. Mapa del Alto Mayo utilizado en las entrevistas y encuestas. Fuente: Gobierno Regional de San Martín, Ministerio del Ambiente del Perú. Elaboración: Daniele Codato.

En lo concerniente a las encuestas, el número total y su distribución han sido definidos en base a diferentes metodologías y enfoques presentes en la literatura científica (McLafferty, 2010, pp. 77-88; Resarch Advisor, 2006), teniendo en cuenta tanto aspectos metodológicos de muestreo estadístico como aspectos prácticos, tales como el tiempo y los recursos disponibles. En particular el número de 400 encuestas ha sido definido tomando en cuenta las indicaciones de la tabla de dimensión de muestreo de Research Advisor (2006), que indica el número de 384 como dimensión de muestreo ideal para una población total igual o superior a 250000 individuos, con un nivel de confianza del $95 \%$ y un margen de error del $5 \%$. Respecto a la definición de la distribución de las encuestas se había considerado las características del área y de los actores presentes, intentando así estratificar los esfuerzos de esta manera: 260 encuestas en el ámbito urbano (la población urbana, que vive en las capitales distritales, es el 65\% del total) y 140 en los centros poblados rurales. Por el ámbito urbano se había planeado realizar 156 encuestas en la provincia de Moyobamba y 104 en la provincia de Rioja. Se pretendía dividir a los actores entre profesores de instituciones educativas primaria o secundaria (debido a que estos son los que pasan los conocimientos a las generaciones futuras), otros actores locales y en la provincia de Rioja se quería considerar también 
a los actores indígenas, siendo el distrito de Awajún poblado principalmente por parte de la etnia que le da el nombre. En lo que respecta a la parte rural, se había planeado llegar a 28 centros poblados, y realizar cinco encuestas por cada uno, posiblemente para entrevistar a un profesor y a cuatro personas de la sociedad civil. Entre los 28 centros poblados rurales se apuntaba a considerar también a las comunidades indígenas, con la finalidad de llegar a seis comunidades nativas awajún, tres en la provincia de Rioja y tres en la provincia de Moyobamba. Los individuos encuestados han sido elegidos de forma aleatoria. Por el trabajo de campo de levantamiento de los datos se capacitaron a siete estudiantes de ingeniería ambiental de la Universidad Nacional de San Martín que apoyaron en el proceso.

En lo concerniente a las entrevistas a actores clave, se han elegido arbitrariamente tres actores estatales y tres de la sociedad civil que formen parte de alguna asociación de una cierta relevancia por capital distrital, además de seis personas del Gobierno regional y seis de ONG u otras asociaciones que operen a nivel regional, para llegar a un total de 106 personas. La elección de este tipo de actores está basada en su grado de conocimiento del territorio del Alto Mayo y de la relevancia de su cargo pasado o presente que le haya permitido conocer y actuar como tomadores de decisiones.

\section{The Social Values for Ecosystem Services - SolVES}

Herramienta que funciona con ESRI ArcGIS desarrollada por el U.S. Geological Survey's (USGS) Rocky Mountain Geographic Science Center (RMGSC) en colaboración con la Colorado State University, que permite evaluar, mapear y cuantificar el valor social percibido de los SE, a través de un índice de valor no monetario, que utiliza los datos recolectados mediante encuestas a diferentes actores sociales. La versión utilizada es la 2.1, desarrollada por el programa ESRI ArcMap 10.x. SolVES permite integrar y usar la información de percepción social del territorio en los procesos de evaluación de los SE como soporte a los tomadores de decisiones y a los actores interesados en la toma de decisiones concernientes a la planificación y gestión de los ecosistemas y del territorio en general. A través de SolVES se pueden producir mapas e información estadística sobre diferentes valores sociales por una determinada área de estudio, combinando la información espacial y no espacial proporcionada por un cuestionario sobre las actitudes y preferencias de diferentes actores sociales con los aspectos físico-ambientales, como la cobertura y uso del suelo, modelos digitales de elevación, distancia desde los ríos o carreteras, etc. Los mapas son producidos a través de la creación de un índice de valor social comprendido entre 0 y 10 que permite, con el uso de una escala cromática, evidenciar los lugares donde un determinado valor social se encuentra más o menos valorizado (Sherrouse et al., 2011; SolVES, 2013). 


\section{Resultados}

\section{Entrevistas y encuestas}

Durante el tiempo a disposición para el trabajo de campo se ha logrado colectar 377 encuestas sobre las 400 planeadas y 99 entrevistas sobre 106. Se ha logrado llevar a cabo entrevistas y encuestas en todas las capitales distritales planeadas en fase de gabinete, mientras que por la parte rural se ha llegado a 23 centros poblados rurales sobre 28 .

\section{Datos sobre los informantes de las entrevistas y encuestas}

En la tabla 2 se puede apreciar la distribución de las 99 entrevistas distribuidas por capital distrital y diferenciadas entre entidad pública (alcalde, gerente, etc.) o de la sociedad civil (ronda campesina, comité de regantes, junta de usurarios, etc.) y entre colono, indígena y mestizo.

Tabla 2. Distribución de las 99 entrevistas

\begin{tabular}{lcccccc}
\hline Capitales & \multicolumn{7}{c}{ Entidad pública Sociedad civil } & Colono & Indígena & Mestizo & Sin datos \\
\hline Bajo Naranjillo & 3 & 3 & 4 & 2 & & \\
Calzada & 3 & 3 & 4 & & 2 & \\
Elias Soplin & 3 & 3 & 2 & & 4 & \\
Habana & 3 & 3 & & & 6 & \\
Jepelacio & 4 & 2 & 4 & & 2 & 7 \\
Moyobamba & 11 & 6 & 1 & 1 & 9 & \\
Naranjos & 3 & 3 & 6 & & & \\
Nueva Cajamarca & 3 & 3 & 5 & & 1 & \\
Posic & 4 & 2 & 3 & & 3 & \\
Rioja & 1 & 3 & 1 & & 3 & \\
San Fernando & 3 & 3 & 2 & & 4 & \\
Soritor & 3 & 3 & 4 & & 2 & \\
Yantalo & 4 & 2 & 5 & & 1 & \\
Yorongos & 3 & 3 & 3 & & 3 & \\
Yuracyacu & 3 & 3 & 2 & & 3 & \\
\hline Total & 59 & 40 & 46 & 3 & 43 & 7 \\
\hline
\end{tabular}

En la tabla 3 se puede apreciar la distribución de las 377 encuestas por capital distrital y centro poblado rural, evidenciando la provincia y el ámbito (urbano y rural), además de distinguir a los actores entre colonos, mestizos e indígenas. Estos datos se pueden apreciar de manera gráfica también en la figura 3 donde se presenta la distribución espacial de las encuestas y entrevistas en el área del Alto Mayo. 
Tabla 3. Distribución de las 377 encuestas

\begin{tabular}{|c|c|c|c|c|c|c|}
\hline Prov. & Ciudades y centros poblados & Colono & Indígena & Mestizo & Sin datos & Total \\
\hline \multirow{6}{*}{ 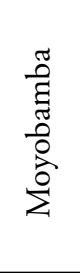 } & Moyobamba & 17 & & 34 & 4 & 55 \\
\hline & Soritor & 12 & & 11 & 13 & 36 \\
\hline & Jepelacio & 13 & & 8 & & 21 \\
\hline & Calzada & 3 & & 6 & 10 & 19 \\
\hline & Habana & 7 & & 9 & & 16 \\
\hline & Yantalo & 9 & & 5 & & 14 \\
\hline \multirow{6}{*}{$\frac{\pi}{2}$} & Rioja & 11 & & 13 & 1 & 25 \\
\hline & Nueva Cajamarca & 20 & & 7 & 1 & 28 \\
\hline & Yorongos & 1 & & 5 & & 6 \\
\hline & Elias Soplin & 11 & & 3 & & 14 \\
\hline & Naranjos (Pardo Miguel) & 8 & & 3 & & 11 \\
\hline & Shampuyacu & & 8 & 1 & & 9 \\
\hline \multirow{8}{*}{ 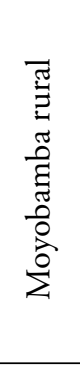 } & Valle la Conquista & 3 & & 2 & & 5 \\
\hline & Flor del Mayo & 5 & & 1 & & 6 \\
\hline & Santa Catalina & 5 & & & & 5 \\
\hline & Pueblo Libre & 4 & & 1 & & 5 \\
\hline & Shucshuyacu & 2 & & 3 & & 5 \\
\hline & Pacaypite & 4 & & 1 & & 5 \\
\hline & Nuevo San Miguel & 5 & & & & 5 \\
\hline & Puerto Motilones & 1 & & 2 & 3 & 6 \\
\hline \multirow{16}{*}{ 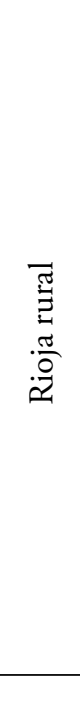 } & Boca Río Soritor & 5 & & & & 5 \\
\hline & Bajo Naranjillo & & 5 & & & 5 \\
\hline & Naciente Río Negro & 6 & & & & 6 \\
\hline & Alto Paraíso & 5 & & & & 5 \\
\hline & Alto Naranjillo & 1 & 4 & & & 5 \\
\hline & Diamante & 2 & & 3 & & 5 \\
\hline & El Triunfo & 3 & & 2 & & 5 \\
\hline & La Florida & 5 & & & & 5 \\
\hline & Miraflores & 5 & & & & 5 \\
\hline & Pto. Bagazan & 5 & & & & 5 \\
\hline & San Juan del Mayo & 2 & 1 & 1 & 1 & 5 \\
\hline & Santa Rosa & 6 & & & & 6 \\
\hline & Tahuantinsuyo & 5 & & 3 & 2 & 10 \\
\hline & Tiwinsa & 2 & & 2 & & 4 \\
\hline & Ucrania & 3 & & 2 & & 5 \\
\hline & Total & 196 & 18 & 128 & 35 & 377 \\
\hline
\end{tabular}




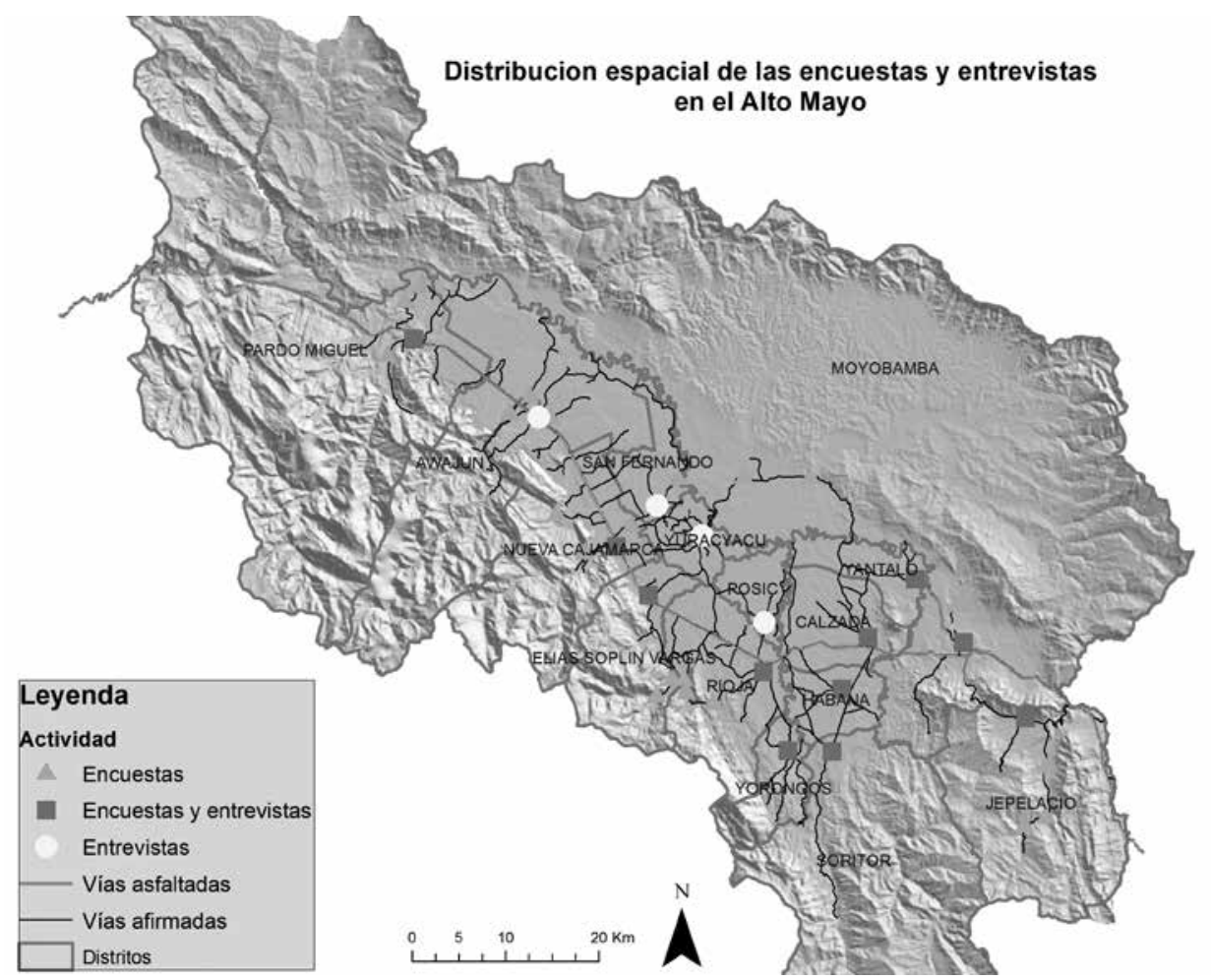

Figura 3. Mapa de distribución de las encuestas y entrevistas. Fuente: Gobierno Regional San Martín, Ministerio del Ambiente del Perú. Elaboración: Daniele Codato.

En las siguentes tablas (4-8) se presentan algunos datos sobre la tipología de entrevistados en las encuestas. Se puede notar en la tabla 5 que el $47,7 \%$ de los participantes tiene educación superior, al contrario de las estadísticas oficiales del INEI (2007) que señalan que la mayoría de la población ha llegado al nivel primario o secundario. Este porcentaje refleja la elección de entrevistar en su mayoria a profesores, que al final del trabajo han sido 138 como se puede apreciar en la tabla 6. La profesión que predomina es la de profesor, seguida por los agricultores-ganaderos y comerciantes quienes sobrepasan a los profesores en las estadísticas del INEI (si no se toma en cuenta a los trabajos no calificados). Como clases de edad se ha elegido entrevistar a personas con más de 20 años, dando preferencia a los adultos con más de 30 años por su mayor conocimiento del área. 
Tabla 4. Sexo de los encuestados

\begin{tabular}{lcc}
\hline Sexo & Total & $\%$ \\
\hline F & 125 & 33.2 \\
M & 251 & 66,6 \\
Sin datos & 1 & 0,3 \\
& & \\
\hline Total & 377 & 100,0 \\
\hline
\end{tabular}

Tabla 6. Profesión de los encuestados

\begin{tabular}{lcc}
\hline Profesión & Total & $\%$ \\
\hline Profesor & 138 & 36,6 \\
Agricultor y/o ganadero & 130 & 34,5 \\
Comerciante & 23 & 6,1 \\
Ama de casa y de niños & 18 & 4,8 \\
Turismo y hotelería & 8 & 2,1 \\
Otros & 43 & 11,4 \\
Sin datos & 17 & 4,5 \\
\hline Total & 377 & 100,0 \\
\hline
\end{tabular}

Tabla 5. Educación de los encuestados

\begin{tabular}{lcc}
\hline Educación & Total & $\%$ \\
\hline Primaria & 77 & 20,4 \\
Secundaria & 104 & 27,6 \\
Superior & 180 & 47,7 \\
Sin datos & 16 & 4,2 \\
\hline Total & 377 & 100,0 \\
\hline
\end{tabular}

Tabla 7. Clase de edad de los encuestados

\begin{tabular}{lcc}
\hline Clases de edad & Total & $\%$ \\
\hline I (20-30) & 41 & 10,9 \\
II (31-40) & 103 & 27,3 \\
III (41-50) & 133 & 35,3 \\
IV (51-60) & 72 & 19,1 \\
V (61+) & 20 & 5,3 \\
Sin datos & 8 & 2,1 \\
& & \\
\hline Total & 377 & 100,0 \\
\hline
\end{tabular}

\section{Resultados principales}

En las siguientes tablas y gráficos se reportan algunos resultados preliminares obtenidos con el procesamiento de las entrevistas y encuestas y que parecen más inherentes con los temas de este artículo. El trabajo de procesamiento y de análisis de los datos estaba todavía en progreso durante la redacción de este artículo, por ello se tiene que considerar estos productos como preliminares consideraciones fruto de estadística descriptiva.

\section{Entrevistas}

Debido a que el proceso de ZEE es la herramienta base del OT en el Perú (Pinasco Vela, 2009), en las tablas 8, 9 y 10 se presentan los resultados de las preguntas sobre los conocimientos y opiniones relativas al estudio de ZEE llevado a cabo en el Alto Mayo. Como se puede ver, aunque la mayoría de los entrevistados tienen conocimiento sobre el proceso, el $41 \%$ considera que no se utiliza todavía en la planificación (entendido como proceso de OT). Otra pregunta importante relativa a la planificación es sobre la importancia de conformar un comité de gestión de cuenca por el Alto Mayo (tabla 11), herramienta considerada importante por casi la totalidad de los actores. 
Tabla 8. Conocimiento proceso ZEE-OT

\begin{tabular}{lcc}
\hline $\begin{array}{l}\text { ¿Conoce usted el proceso } \\
\text { de ZEE-OT? }\end{array}$ & Total & $\%$ \\
\hline $\begin{array}{l}\text { He oído hablar, pero no sé } \\
\text { bien que es }\end{array}$ & 29 & 29,3 \\
No & 19 & 19,2 \\
Sí & 51 & 51,5 \\
\hline Total & 99 & 100,0 \\
\hline
\end{tabular}

Tabla 10. Aplicación ZEE

\begin{tabular}{lcc}
\hline $\begin{array}{l}\text { ¿Se aplica la ZEE en la } \\
\text { planificación? }\end{array}$ & Total & $\%$ \\
& & \\
\hline No & 41 & 41,4 \\
Sí & 35 & 35,4 \\
No sabe/no contesta & 23 & 23,2 \\
\hline Total & 99 & 100,0 \\
\hline
\end{tabular}

Tabla 9. Importancia ZEE

\begin{tabular}{lcc}
\hline $\begin{array}{l}\text { ¿Considera usted que la } \\
\text { ZEE es importante? }\end{array}$ & Total & $\%$ \\
\hline No & 9 & 9,2 \\
Sí & 68 & 68,7 \\
No sabe/no contesta & 22 & 22,2 \\
\hline Total & 99 & 100,0 \\
\hline
\end{tabular}

Tabla 11. Conformación comité de cuenca

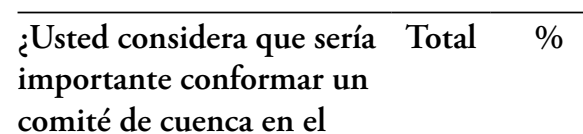

Alto Mayo?

\begin{tabular}{lcc}
\hline No & 1 & 1,0 \\
Sí & 98 & 99,0 \\
& & \\
\hline Total & 99 & 100,0 \\
\hline
\end{tabular}

\section{Encuestas}

En la tabla 12 se presentan los resultados de la pregunta sobre el conocimiento del concepto de Servicios Ecosistémicos. Se han reclasificado las tres respuestas originarias (no conozco, he oído hablar pero no me acuerdo bien de que se trata y si he oído de ellos) utilizando la definición que cada entrevistado daba al concepto, según si se acercaba o menos a la definición del Millenium Ecosystem Assessment (MA, 2005). Como se puede ver, es solo el $21 \%$ que seguramente conoce el concepto y el $4,2 \%$ ha dado una definición correcta aunque diga que no se acuerda bien de qué se trata. Se puede presumir que no conozcan en absoluto el concepto de SE el 28,4\% (no conozco) más el 24,9\% (he oído hablar, pero no me acuerdo bien de qué se trata, sin dar una definición al concepto) y el 16,4\% (sí, pero con una definición equivocada). Esto podría ser indicativo de la poca difusión que todavía tiene este concepto y de la confusión que aún se encuentra en el manejo y desarrollo de proyectos sobre SE. Gracias a la frecuencia de las palabras presentes en las definiciones correctas se ha podido elaborar la figura 4 que presenta un análisis textual cuantitativo generado utilizando la herramienta wordle (www.wordle.net), donde se pueden apreciar las diferentes palabras relativas al concepto de $\mathrm{SE}$ en tamaños diferentes según el número de veces que han sido utilizadas. 
Tabla 12. Conocimiento del concepto de SE

\begin{tabular}{lcc}
\hline ¿Ha oído hablar sobre los SA? & Total & $\%$ \\
\hline $\begin{array}{l}\text { No conozco } \\
\text { He oído hablar pero no me acuerdo bien de qué se trata }\end{array}$ & 107 & 28,4 \\
sin definición & 24,9 \\
He oído hablar pero no me acuerdo bien de qué se trata & 13 & 3,4 \\
con definición equivocada/no comprensible & 16 & 4,2 \\
No me acuerdo bien de que se trata con definición correcta & 79 & 21,0 \\
Sí, he oído de ellos & 62 & 16,4 \\
Sí, pero definición equivocada/no comprensible & 4 & 1,1 \\
Sí, pero sin definición & 2 & 0,5 \\
No contesta & 377 & 100,0 \\
\hline Total & & \\
\hline
\end{tabular}

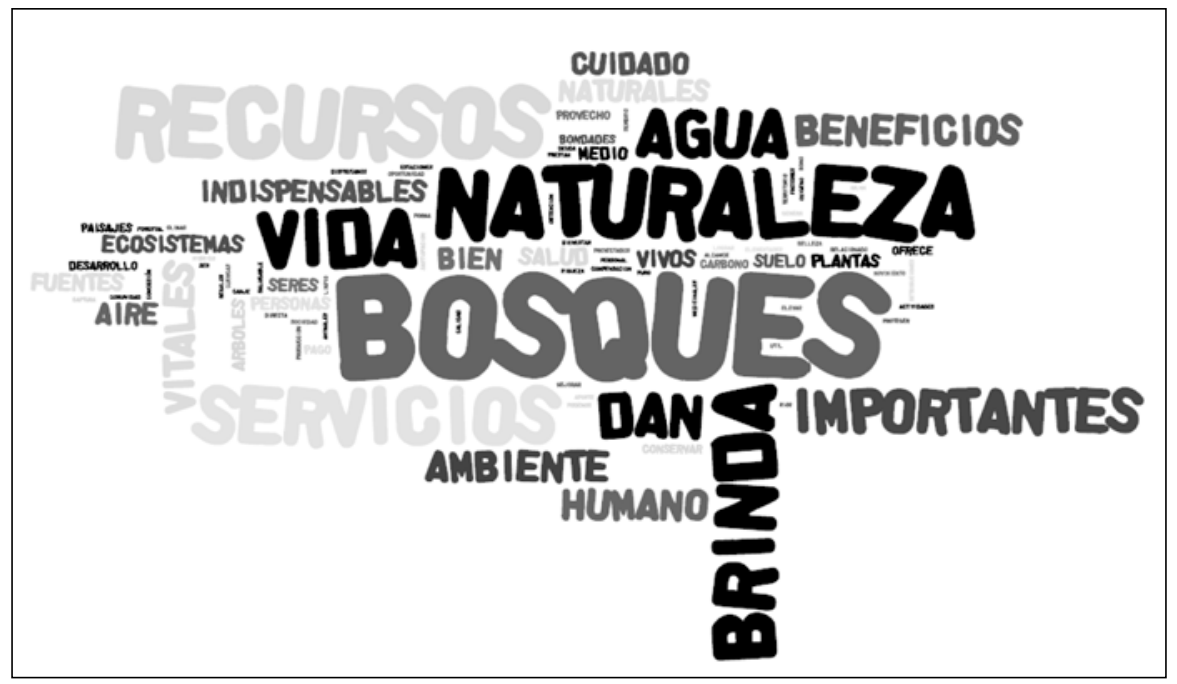

Figura 4. Las palabras más utilizadas en la definición de SE procesadas a través de www.wordle.net

En las tablas 13-15 se presentan algunas preguntas inherentes a los procesos de ZEE-OT y de gestión ambiental. La tabla 13 evidencia que la mayoría de las personas están conscientes de la presencia de una o más áreas de conservación y las tablas 14 y 15 relativas al estudio ZEE que el 60\% ha escuchado hablar de este, pero solo el 13\% declara haber tenido la oportunidad de participar. 
Tabla 13. Conocimiento sobre áreas de conservación

\begin{tabular}{lcc}
\hline $\begin{array}{l}\text { ¿Sabe si hay una o más áreas } \\
\text { de conservación en la zona? }\end{array}$ & Total & $\%$ \\
\hline No & 59 & 15,6 \\
Sí & 317 & 84,1 \\
Sin datos & 1 & 0,3 \\
\hline Total & 377 & 100,0 \\
\hline
\end{tabular}

Tabla 14. Conocimiento sobre la ZEE-OT

\begin{tabular}{lcc}
\hline $\begin{array}{l}\text { ¿Ha escuchado hablar de } \\
\text { la ZEE-OT? }\end{array}$ & Total & $\%$ \\
\hline No & 144 & 38,2 \\
Sí & 228 & 60,5 \\
No sabe/no contesta & 5 & 1,3 \\
\hline Total & 377 & 100,0 \\
\hline
\end{tabular}

Tabla 15. Participación en el proceso de ZE-OT

\begin{tabular}{lcc}
\hline $\begin{array}{l}\text { Ha tenido la oportunidad de } \\
\text { participar del proceso de ZEE-OT? }\end{array}$ & Total & $\%$ \\
\hline No & 322 & 85,4 \\
Sí & 49 & 13,0 \\
No sabe/no contesta & 6 & 1,6 \\
\hline Total & 377 & 100,0 \\
\hline
\end{tabular}

\section{Opinión sobre actividades/usos e importancia de los valores sociales}

En las figuras 5 y 6 se encuentran los resultados de las opiniones sobre ciertas actividades o usos que se desarrollan o podrían desarrollarse en un futuro en el territorio del Alto Mayo respectivamente por las entrevistas y las encuestas, expresado en porcentaje (MC: muy en contra, C: en contra, F: a favor, MF: muy a favor). Como se puede ver, los dos gráficos evidencian como la totalidad de los dos diferentes grupos de actores están a favor o muy a favor de la creación de áreas naturales protegidas de diferente tipología y al ecoturismo, mientras están en contra de la extracción de madera de los bosques protegidos como el BPAM, resultados que al parecer evidencian un alma "ecologista» por parte de estos actores, aunque estas opiniones necesitan una profundización antes de obtener conclusiones definitivas. Los dos grupos de actores están mayormente a favor del incremento de carreteras, probablemente considerada como infraestructura fundamental para el desarrollo económico del área. Es Interesante ver como los actores de las encuestas están más a favor de la colonización e incremento de centros poblados con respecto a los de las entrevistas, se tendrá que estudiar la influencia de los colonos o de la parte rural en esto. Otro punto que se quiere evidenciar es el número más alto de personas de las encuestas que está a favor del café y del cacao cultivados de manera tradicional con respecto a las entrevistas; aunque se sepa que es una actividad con impacto ambiental, pues, para ellos es una de las principales fuentes de ingreso del área. 
De todas formas se puede ver como casi todos estarían a favor del café y del cacao llevados con técnicas agroforestales más sustentables. También, otras actividades impactantes como el cultivo de arroz o la ganadería tradicional resultan más aceptadas por los de las encuestas.

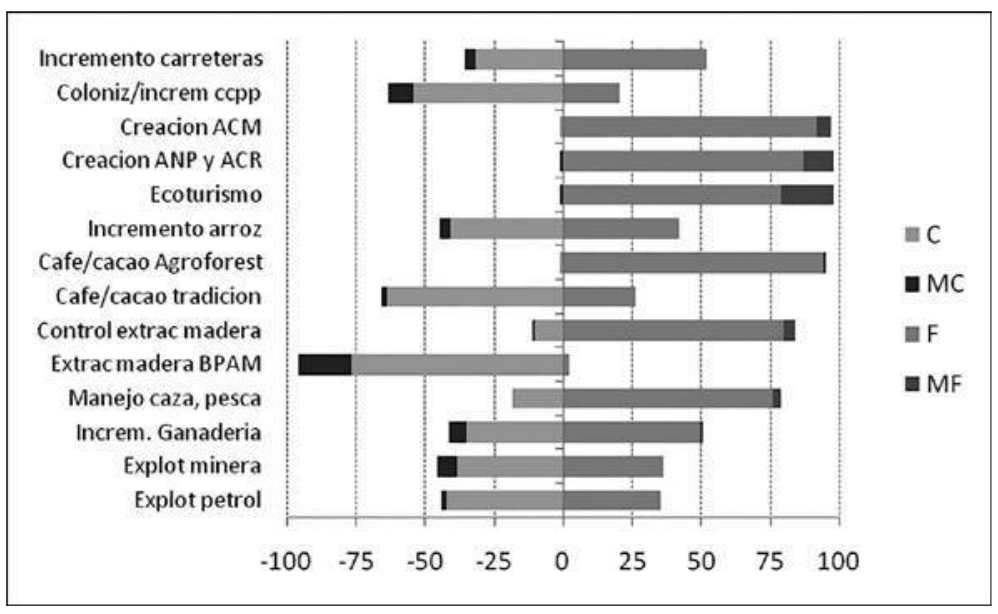

Figura 5.99 entrevistas. Opiniones sobre actividades/usos del Alto Mayo

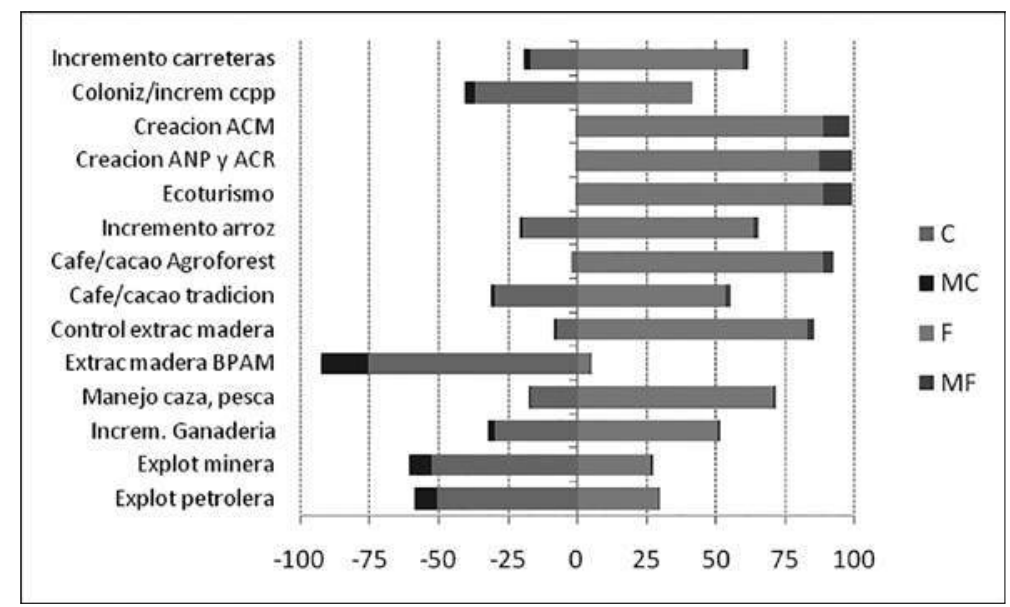

Figura 6. 377 encuestas. Opiniones sobre actividades/usos del Alto Mayo

En las figuras 7 y 8 se presentan el ordenamiento de prioridades con respecto a los valores sociales percibidos del territorio del Alto Mayo (desde el 7 como más importante hacia el 1 como menos importante). Como se puede ver tanto por las entrevistas como por las encuestas, el valor más importante es el valor de sustento para la vida, o sea 
los lugares o áreas donde se genera, produce y renueva el agua, probablemente visto como el recurso más importante y que sustenta todas las otras actividades además de la vida humana. Luego siguen los valores de uso, biodiversidad y de paisaje, aunque de manera un poco diferente en las entrevistas con respecto a las encuestas. En los últimos lugares como importancia se encuentran el valor espiritual/cultural y el valor histórico, esto tal vez debido a la gran presencia de colonos que no tienen estos tipos de relaciones con el área.

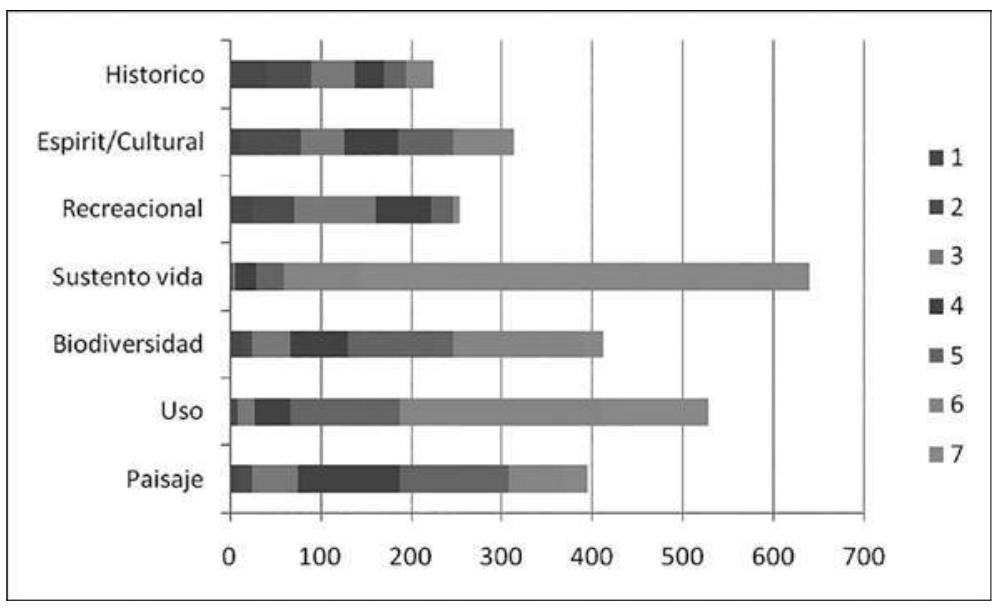

Figura 7.99 entrevistas. Orden de prioridad de los valores sociales percibidos por el Alto Mayo

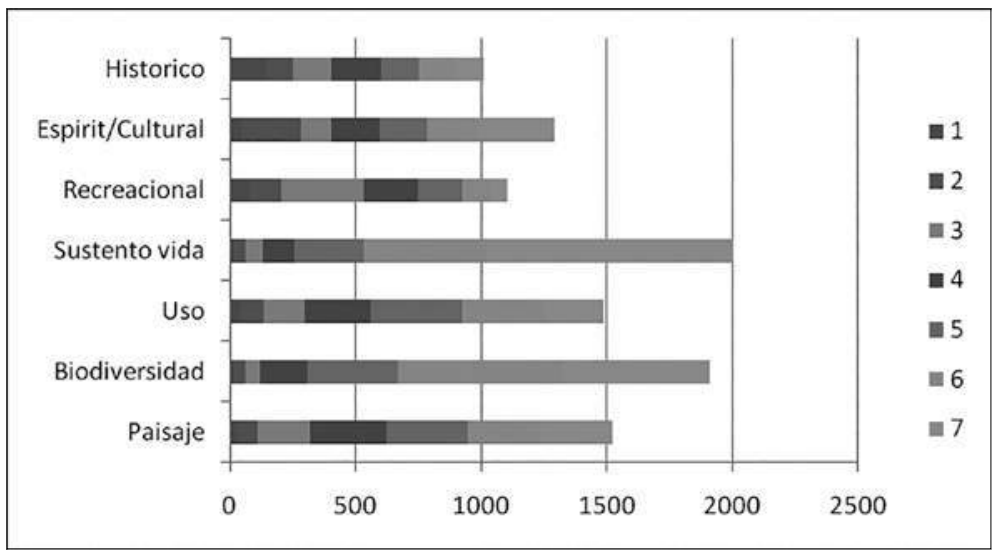

Figura 8. 377 encuestas. Orden de prioridad de los valores sociales percibidos por el Alto Mayo 


\section{The Social Values for Ecosystem Services (SolVES)}

En esta parte se presenta un ejemplo de los mapas que se pueden obtener utilizando la herramienta SolVES. Debido a la complejidad de los modelos y estadísticas detrás de la herramienta y de las modalidades de digitalización de los puntos y de la diferente información ambiental que se puede introducir, el proceso de elaboración e interpretación de los resultados ha necesitado bastante tiempo.

En la figura 9 se puede ver el conjunto de los puntos ubicados en los mapas con respecto al valor de sustento para la vida por los actores de las entrevistas que estaban a favor de la creación de áreas de conservación nacionales o regionales. Estos puntos luego han sido procesados con SolVES junto con información espacial (en formato raster) sobre el uso y cobertura del suelo, las diferentes subcuencas hidrográficas, el área ocupada por el BPAM y por las otras formas de conservación del Sistema Regional de Conservación (SRC). Los puntos que indicaban de manera general un área muy amplia como puede ser el BPAM han sido ubicados todos en una misma área elegida de manera arbitraria, mientras que los puntos que indicaban lugares específicos han sido colocados de la manera más precisa posible utilizando la información georreferenciada del Gobierno regional.

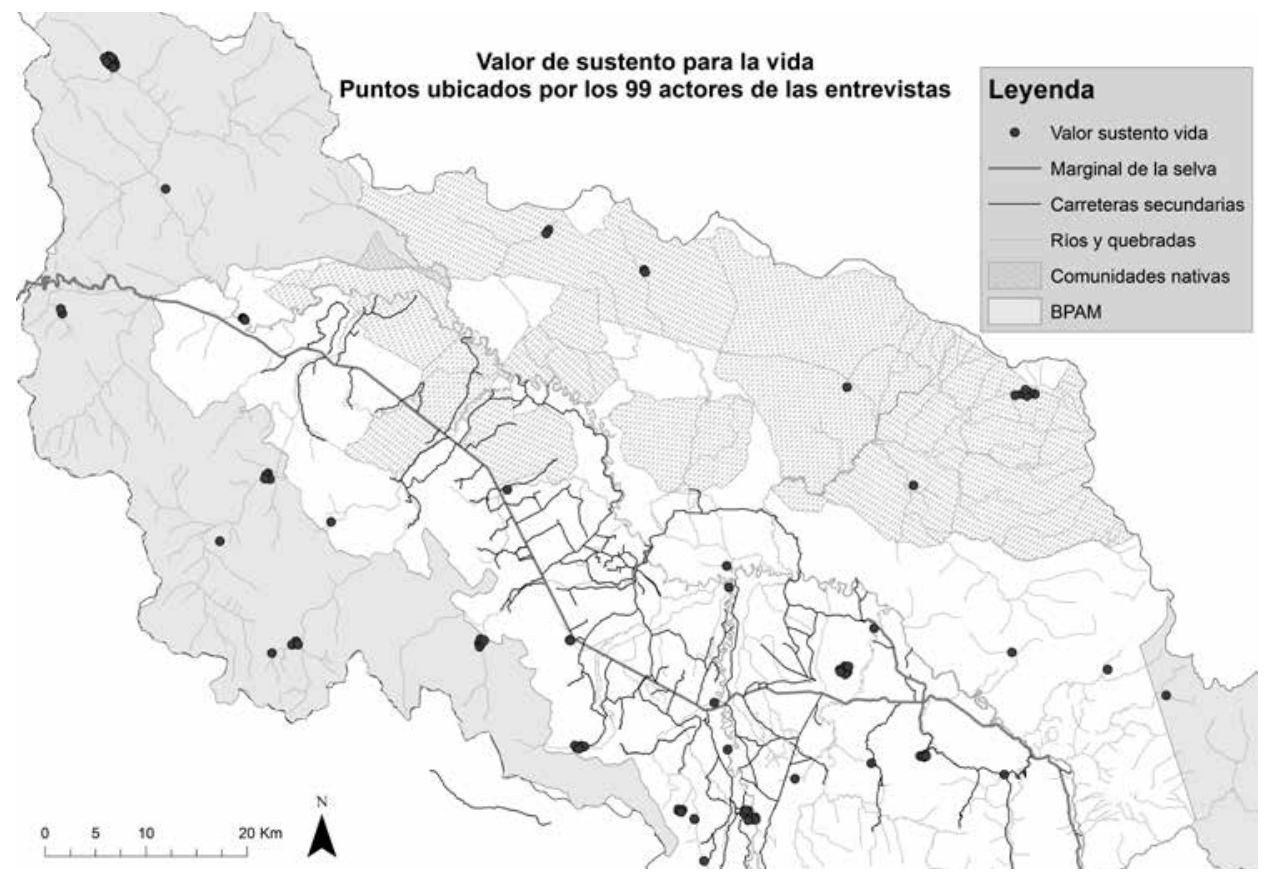

Figura 9. Mapa con los puntos ubicados por los 99 actores de las entrevistas con respecto al valor de sustento para la vida. Fuente: Gobierno Regional de San Martín, Ministerio del Ambiente del Perú. Elaboración: Daniele Codato. 
En la figura 10 se puede ver el resultado presentado a través de un mapa del área donde con diferentes colores correspondientes a un índice de valor social de 0 a 10, se evidencian las áreas donde los actores perciben la presencia de un valor más alto (colores graduales desde el amarillo hacia el rojo) o menos alto (del azul hacia el blanco). Además, se presentan estadísticas sobre la relación entre los puntos y la información ambiental incluida en la elaboración. Sin entrar en detalle se puede ver cómo las áreas más valorizadas corresponden al Morro de Calzada que brinda agua al distrito de Calzada y a las microcuencas del Rumiyacu, Mishquiyacu y Almendra que producen el agua actualmente utilizada en Moyobamba. Es muy valorizada también la subcuenca del río Gera que alimenta una hidroeléctrica y el BPAM, sobre todo en la margen derecha del río Mayo en la provincia de Rioja, donde reside la mayor parte de los entrevistados.

\section{SolVES Entrevistas totales}

Valor de sustento para la vida
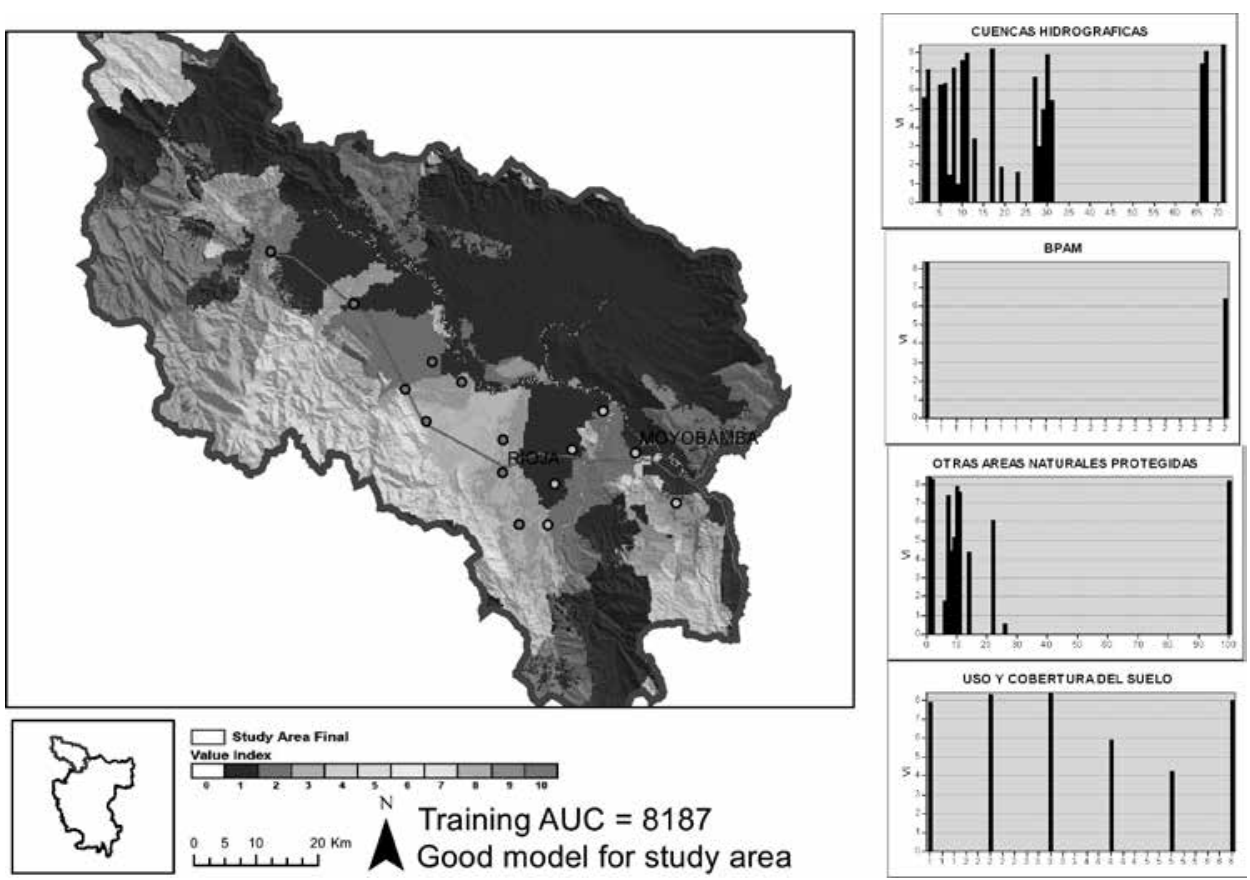

Figura 10. Mapa elaborado con la herramienta SoLVES. Fuente: Gobierno Regional de San Martín, Ministerio del Ambiente del Perú. Elaboración: Daniele Codato. 


\section{CoNClusiones, PROBLEMÁticas y tAREAS PENDIENTES}

Con este artículo se ha presentado un estudio sobre la percepción, opinión y conocimiento de algunos actores residentes en el Alto Mayo sobre su territorio, en particular tomando en consideración los servicios ecosistémicos, los que están cada vez más reconocidos como un componente fundamental en los procesos de ordenamiento territorial y en la conservación de los ecosistemas. En este análisis se expone el trabajo desarrollado hasta julio de 2013 y que se presentó como ponencia durante el «X Congreso Nacional y V Congreso de Geografía de las Américas Dr. Efraín Orbegoso Rodríguez», que tuvo lugar desde el 3 hasta el 5 de octubre de 2013 en la ciudad de Trujillo, a pesar de que la investigación finalizó en septiembre de 2014.

Con este trabajo se quería dar voz a algunos actores de la sociedad civil, como profesores y agricultores quienes son los que directamente actúan y viven en el territorio con impactos tanto positivos como negativos y que a menudo no son tomados en cuenta en los procesos de ordenamiento territorial y gestión ambiental, como se ha podido observar en las preguntas sobre la zonificación ecológico económica. Las opiniones respecto a ciertos usos y actividades implementadas o con posibilidad de establecerse en un futuro en el área del Alto Mayo pueden contribuir a entender la visión de desarrollo que estos actores tienen y por ende las posibilidades de éxito de los proyectos de conservación llevados a cabo por el Gobierno Regional y las diferentes ONG.

Se ha presentado también la herramienta Social Values for Ecosystem Services SolVES, que puede ser un valioso soporte a estos tipos de estudios de percepción social y que permite obtener mapas y estadísticas útiles, por ejemplo para priorizar áreas de intervención o entender si la percepción del territorio corresponde a los estudios científicos de carácter biofísico. Además, la conexión que SolVES hace entre las variables ambientales como uso y cobertura del suelo y los puntos priorizados por parte de los actores, puede permitir entender cuáles son las condiciones ambientales que son percibidas como mejores por ciertos tipos de valores sociales de los SE (Sherrouse et al., 2011; Van Riper et al., 2012).

Quedaba como tarea pendiente ver si hay necesidad de complementar los datos recolectados hasta ese entonces y seguir con el procesamiento de los datos a través de diferentes estadísticas, en particular comparar los resultados de los actores involucrados en las entrevistas con los actores de las encuestas; ver si hay diferencias de opiniones y respuestas entre la parte rural y urbana o entre colonos y mestizos; y si los resultados se pueden inferir a la población o por lo menos a una parte de esta. También con SolVES se tenían que hacer pruebas para producir mapas combinando diferentes tipos de información ambiental con los puntos obtenidos y comparar los resultados entre ellos y con los estudios científicos a disposición del territorio. 
El trabajo no ha estado exento de problemas, empezando por la preparación de las entrevistas y cuestionarios, que debían ser lo más simple y rápidos posibles ya que a menudo se entrevistaba a la gente en su lugar de trabajo. También, el trabajo con el mapa fue bastante complicado y probablemente habría sido más eficaz si se hubiera utilizado como herramienta durante talleres en los cuales los actores hubieran estado más involucrados y con más tiempo disponible.

Un factor que podría haber aumentado el margen de error fue la recolección de información por parte de diferentes personas, aunque estuvieron capacitadas en la tarea.

\section{BibLIOgRAFÍA}

AMPA - Amazónico por la Amazonía (2012). Ordenamiento Jurídico del Departamento de San Martín. Instrumento para el establecimiento de una politica territorial. Moyobamba. No publicado.

Bagstad, K. J., Semmens, D. J., Waage, S. y Winthrop, R. (2013). A comparative assessment of decision-support tools for ecosystem services quantification and valuation. Ecosystem Services, 1-13. http://dx.doi.org/10.1016/j.ecoser.2013.07.004

Brown, G. (2005). Mapping Spatial Attributes in Survey Research for Natural Resource Management: Methods and Applications. Society \& Natural Resources, 18(1), 17-39. http://dx.doi.org/10.1080/08941920590881853

Brown, G., Montag, J. M. y Lyon, K. (2012). Public Participation GIS: A Method for Identifying Ecosystem Services. Society \& Natural Resources, 25(7), 633-651. http:// dx.doi.org/10.1080/08941920.2011.621511

Burkhard, B., Kroll, F., Nedkov, S. y Müller, F. (2012). Mapping ecosystem service supply, demand and budgets. Ecological Indicators, 21, 17-29. http://dx.doi.org/10.1016/j. ecolind.2011.06.019

Busch, M., Notte, A. La, Laporte, V. y Erhard, M. (2012). Potentials of quantitative and qualitative approaches to assessing ecosystem services. Ecological Indicators, 21, 89103. http://dx.doi.org/10.1016/j.ecolind.2011.11.010

Costanza, R., d'Arge, R., de Groot, R., Farber, S., Grasso, M., Hannon, B., Limburg, K., Naeem, S., O’Neill, R.V., Paruelo, J., Raskin, R.G., Sutton, P. y van den Belt, M. (1997). The value of the world's ecosystem services and natural capital. Nature 387, 253-260. http://dx.doi.org/10.1038/387253a0

De Marchi, M. y Scolozzi, R. (2012). La valutazione economica dei servizi ecosistemici e del paesaggio nel Parco Naturale Adamello Brenta. Valutazione Ambientale, 22, 54-61.

Dunn, C. (2007). Participatory GIS - A People's GIS? Progress in Human Geography 31(5), 616-637. http://dx.doi.org/10.1177/0309132507081493

Gobierno Regiónal de San Martín, Proyecto Especial Alto Mayo, Instituto de Investigaciones de la Amazonía Peruana, Deutsche Gesellschaft für Technische Zusammen- 
arbeit GmbH. (2007). Zonificación Ecologico-Economica de la cuenca del Alto Mayo. Moyobamba.

Gobierno Regional de San Martín, Instituto de Investigaciones de la Amazonía Peruana, Deutsche Gesellschaft für Technische Zusammenarbeit GmbH. (2009). Las potencialidades y limitaciones del departamento de San Martín. La Zonificación EcologicoEconomica como base para el Ordenamiento Territorial. Moyobamba.

Gómez-Baggethun, E., de Groot, R., Lomas, P. L. y Montes, C. (2010). The history of ecosystem services in economic theory and practice: From early notions to markets and payment schemes. Ecological Economics, 69(6), 1209-1218. http://dx.doi. org/10.1016/j.ecolecon.2009.11.007

INEI (2007), Instituto Nacional de Estadística e Informática. XI Censo Nacional de Población y VI Censo Nacional de Vivienda. Disponible en: http://www.inei.gob.pe/.

INEI (2013), Instituto Nacional de Estadística e Informática. http://www.inei.gob.pe/. Consultado el 16/01/2013.

León, F., Moncayo, M. C. y Renner, I. (2010). Compensación por servicios ecosistémicos: Lecciones aprendidas de una experiencia demostrativa. Las microcuencas Mishiquiyacu, Rumiyacu y Almendra de San Martín, Perú. Lima: Minam.

MA - Millennium Ecosystem Assessment (2005). Ecosystems and Human Well-Being. Synthesis. Washington DC: Island Press.

McLafferty, S. L. (2010). Conducting Questionnaire Surveys. En Clifford, N., French, S. y Valentine, G. (eds.), Key methods in Geography. ${ }^{\text {nd }}$ Edition (pp. 77-88). Londres: SAGE Publication Ltd.

Minam - Ministerio del Ambiente (2013). Guía Metodológica para la Elaboración de los Instrumentos Técnicos Sustentatorios para el Ordenamiento Territorial. Lima: Minam.

Pérez Celis, I. (2011). Diagnóstico sobre la situación de las comunidades nativas en el proceso de la zonificación ecológica económica y el ordenamiento territorial en el departamento de San Martín. CAAAP. Tarapoto. No publicado.

Pinasco Vela, K. (2009). Guía de Ordenamiento Territorial para Gobiernos Locales. Lima: Minam.

Proyecto Segunda Comunicación Nacional de Cambio Climático (2009). Evaluación local integrada y estrategia de adaptación al cambio climático en el río Mayo. Lima: Minam.

Quintero, M. (ed.) (2010). Servicios ambientales hidrológicos en la región andina. Estado del conocimiento, la acción y la política para asegurar su provisión mediante esquemas de pago por servicios ambientales. Agua y Sociedad, 12; Serie Panorama Andino, 1. Lima: IEP y Condesan.

Reátegui, S. (2012). San Martín - Region Verde. Presentación en Power Point. No publicado. Resarch Advisor (2006). Sample size table. Disponible en http://www.research-advisors. com/tools/SampleSize.htm. 
Rojas, I. (2012). Sistema Regional de Conservación. Presentación en Power Point. No publicado.

Sherrouse, B. C., Clement, J. M. y Semmens, D. J. (2011). A GIS application for assessing, mapping, and quantifying the social values of ecosystem services. Applied Geography, 31(2), 748-760. http://dx.doi.org/10.1016/j.apgeog.2010.08.002

SolVES, (2013). The Social Values for Ecosystem Services. Disponible en: http://solves. cr.usgs.gov/.

Van Riper, C. J., Kyle, G. T., Sutton, S. G., Barnes, M. y Sherrouse, B. C. (2012). Mapping outdoor recreationists' perceived social values for ecosystem services at Hinchinbrook Island National Park, Australia. Applied Geography, 35(1-2), 164-173. http://dx.doi. org/10.1016/j.apgeog.2012.06.008

Fecha de envío: 30 junio, 2015 Fecha de aceptación: 5 diciembre, 2015 